\title{
Long WavelengthPhotochemistry of Ozone and n-butylferrocene: a Matrix Isolation Study
}

\author{
Laura F. Pinelo and Bruce S. Ault* \\ Department of Chemistry \\ University of Cincinnati \\ Cincinnati, $\mathrm{OH}$ 45221-0172
}

\begin{abstract}
The photochemical reaction of ozone and n-butylferrocene has been studied using a combination of argon-matrix isolation, infrared spectroscopy, and theoretical calculations. The dark deposition produced a vivid green matrix that, when irradiated with red light, turned a brownish-red color.This green matrix as well as slightly red-shifted $\mathrm{O}_{3}$ infrared absorptions are indicative of the formation an initial charge transfer complex between ozone and nbutylferrocene. The spectral resultssupport the photodissociation of the complexed ozone with red light $(\lambda \geq 600 \mathrm{~nm})$ producing an oxygen atom, $\mathrm{O}\left({ }^{3} \mathrm{P}\right)$, and a dioxygen molecule, $\mathrm{O}_{2}\left({ }^{3} \Sigma\right)$. The $\mathrm{O}\left({ }^{3} \mathrm{P}\right)$ then reacts with n-butylferrocene to form products consisting of an iron atom with a coordinated n-butylcyclopentadienyl or cyclopentadienyl ring and either: (1) a pyran, (2) an aldehyde, or (3) a bidentate cyclic aldehyde with a seven-membered ring including the iron atom. The photochemical products were characterized with FT-IR spectroscopy, ${ }^{18}$ O-labeled $\mathrm{O}_{3}$ experiments, and DFT calculations using the B3LYP functional with the $6-311++\mathrm{G}(\mathrm{d}, 2 \mathrm{p})$ basis set. A possible mechanism for the photochemical reaction is discussed.
\end{abstract}


Keywords: matrix isolation, infrared spectra, theoretical calculations, photodissociation, oxidation, mechanism

\section{Introduction}

The use of organometallic compounds such as ferrocene as precursors for the formation of metal oxide thin films has become an area of intense study over the last decade. ${ }^{1-5}$ In general, metal oxide thin films play an important part in our lives; they are used in flat panel displays, energy saving window coatings, solar cells, and a variety of other devices. ${ }^{6-8}$ Thin films are primarily generated by techniques such as atomic layer deposition (ALD), chemical vapor deposition (CVD) or physical vapor deposition (PVD). ${ }^{9-11}$ PVD techniques, such as evaporation or sputtering, involve the adsorption of the vaporized material onto the substrate to form the thin film. ${ }^{9}$ CVD is a process that involves the formation of a thin film of solid reaction product on a substrate by the reaction of gas phase precursors. ${ }^{10,11}$ In CVD, metal oxide thin films are often prepared by reacting a volatile organometallic compound with an oxygen source. ${ }^{11}$ Increasingly, ozone is being used as the oxygen source because it has a high oxidation potential, it contains only oxygenand it is volatile, leading to rapid and effective metal oxide thin film formation. ${ }^{12-15}$

Thin films containing iron oxide have been of particular interest and the subject of numerous research papers. They have been used in photochemical cells, batteries, and gas sensors. ${ }^{16-21}$ Metallocenes are one class of iron precursors used in the CVD of iron-oxidecontaining thin films. ${ }^{2}$ This class includes ferrocene $\left(\mathrm{cp}_{2} \mathrm{Fe}\right)$ and n-butylferrocene (n-butyl $\mathrm{cp}_{2} \mathrm{Fe}$ ), which have been investigated for use as an iron precursor in CVD. ${ }^{1,2,22}$ n-Butylferrocene, like ferrocene, has several advantages over other iron precursors since it is relatively inexpensive, thermally stable, neither air nor moisture sensitive, and vaporizes cleanly. nButylferrocene has also been used in CVD as a co-precursor with nickelocene and oxygen to 
form a thin film of nickel ferrite $\left(\mathrm{NiFe}_{2} \mathrm{O}_{4}\right)$. The nickel ferrite thin film is of particular interest due to its potential for application in microelectronic devices. ${ }^{22}$

Recently a matrix isolation study of the reaction of ferrocene $\left(\mathrm{cp}_{2} \mathrm{Fe}\right)$ and ozone $\left(\mathrm{O}_{3}\right)$ was conducted by Kugel et al. ${ }^{23}$ This study used matrix-isolation combined with IR spectroscopy and theoretical calculations to show that a photochemical reaction of $\mathrm{O}_{3}$ with $\mathrm{cp}_{2} \mathrm{Fe}$ occurs upon irradiation with red light $(\lambda \geq 600 \mathrm{~nm})$. Thislow-energyphotochemical reaction leads to the production atomic oxygen $\mathrm{O}\left({ }^{3} \mathrm{P}\right)$ which subsequently reacts with $\mathrm{cp}_{2} \mathrm{Fe}$ resulting in the formation of an iron cyclopentadienyl ring moiety and ether: (1) a pyran, (2) an aldehyde, or (3) a bidentate cyclic aldehyde with a seven-membered ring including the iron atom. It should be noted that a dark green matrix was observed prior to irradiation and this color was attributed to a charge transfer complex between $\mathrm{O}_{3}$ and $\mathrm{cp}_{2} \mathrm{Fe}\left(\mathrm{cp}_{2} \mathrm{Fe}-\mathrm{O}_{3}\right)$. The present work investigates the photochemical reaction of $\mathrm{O}_{3}$ with n-butylferrocene (n-butyl $\mathrm{cp}_{2} \mathrm{Fe}$ ), and it explores the effect of the n-butyl substituent on the reaction and the observed products. The study was done using the low-temperature technique of matrix-isolation combined with FT-IR spectroscopy and theoretical calculations. Matrix-isolation has the potential to trap and stabilize reactive species, such as early intermediates, and allows for their characterization by spectroscopy.

\section{Experimental Section}

Ozone $\left(\mathrm{O}_{3}\right)$ was produced by the Tesla coil discharge of molecular oxygen $\left(\mathrm{O}_{2}\right)($ Wright Brothers) while being condensed with liquid nitrogen. Excess $\mathrm{O}_{2}$ was pumped off prior to the ozone being warmed to room temperature. The $\mathrm{O}_{3}$ was then transferred to a mixing can where it was diluted with argon (Ar) (Wright Brothers, 99.998\%) in an $\mathrm{Ar} / \mathrm{O}_{3}$ ratio of $\approx 250$. Stock nbutylferrocene (n-butyl $\mathrm{cp}_{2} \mathrm{Fe}$ ) (Strem Chemicals, 99\%) was purified by sublimation. The $\mathrm{n}$ butyl $\mathrm{cp}_{2}$ Fewas placed in a sample holder that was heated with a sand bath at a temperature of 
$\sim 45^{\circ} \mathrm{C}$ causing vaporization. The sample holder was attached by an Ultra-Torr ${ }^{\circledR}$ tee to the deposition line where the vaporized n-butyl $\mathrm{cp}_{2} \mathrm{Fe}$ mixed with pure argon. All experiments were conducted using a standard matrix isolation system and the twin jet (TJ) configuration as previously described. ${ }^{24}$ The matrix was deposited in the dark onto a CsI cold window over 24 hours and deposition was stopped prior to the collection of the first spectrum. Spectra were collected with a Perkin-Elmer Spectrum One infrared spectrometer at $1 \mathrm{~cm}^{-1}$ resolution. In order to minimize the exposure of the matrix to the spectrometer source prior to irradiation, the windows were covered during deposition. The matrix was then irradiated using the output from an incandescent light bulb filtered through a red glass cutoff filter (Corning red glass filter \#2418, transmits $\lambda \geq 600 \mathrm{~nm}$ ) or an infrared cutoff filter (Schott infrared glass filter RG1000, transmits $\lambda \geq 1000 \mathrm{~nm}$ ) for 30 minutes each. Spectra were collected after each irradiation.

\section{Computational Details}

The calculations were performed with the Gaussian 09 suite of programs ${ }^{25}$ using density functional theory (DFT), at the Becke, three-parameter, Lee-Yang-Parr (B3LYP) functional and with the $6-311++\mathrm{G}(\mathrm{d}, 2 \mathrm{p})$ basis set. Complete geometry optimizations, infrared vibrational frequencies, and energies for all species and were obtained at this level of theory, a level that has been shown to be a cost effective way to successfully predict the structures and properties of the species of interest. Transition states and IRC calculations were also done at this level. This method provides calculated infrared vibrational frequencies within $\pm 3 \%$ agreement with the experimentally observed bands and ${ }^{18} \mathrm{O}$-isotope shifts within $\pm 2 \mathrm{~cm}^{-1}$ of the experimentally observed shifts. Charge distribution results are from natural bond orbital (NBO) analyses of the optimized species.

\section{Results and Discussion}


Blank spectra including deposition, annealing, and irradiation were obtained for both parent compounds in argon prior to conducting codeposition experiments. These blanks showed excellent agreement with both literature and calculated spectra. ${ }^{26,27} \mathrm{~A}$ list of the calculated infrared vibrational frequencies and intensities forn-butyl $\mathrm{cp}_{2}$ Feis provided in Table S1a. The calculated ring conformation of n-butyl $\mathrm{cp}_{2} \mathrm{Fe}$ is eclipsed (Figure 1a) and a stable staggered conformation could not be located. The calculated eclipsed conformation for n-butyl $\mathrm{cp}_{2} \mathrm{Fe}$ is consistent with that of the experimentally determined gas phase structures of methylferrocene and ethynylferrocene. ${ }^{28,29}$

(a)

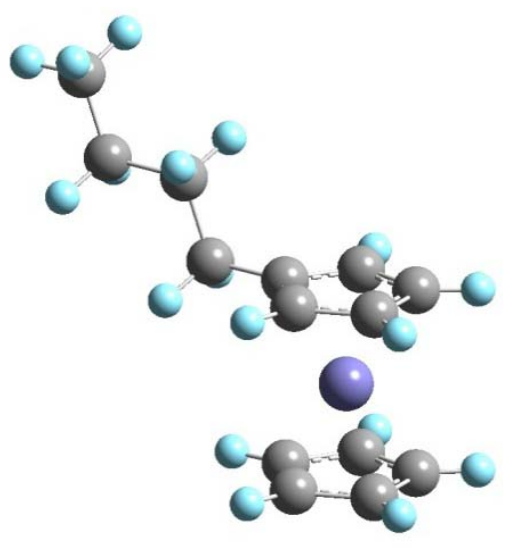

(b)

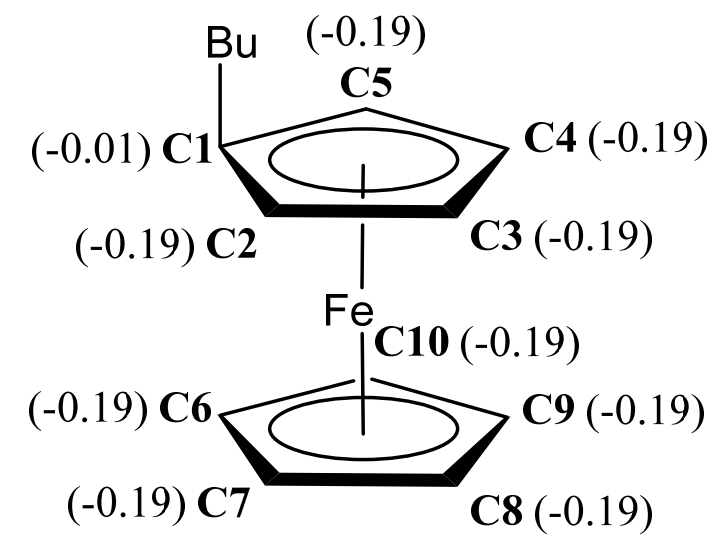

Figure 1 (a) Gaussian optimized structure of n-butylferrocene. (b) The charge density of and the designations for the n-butyl $\mathrm{cp}_{2} \mathrm{Fe}$ ring carbons. 
Early results of the $\mathrm{Ar} / \mathrm{O}_{3}$ and $\mathrm{Ar} / \mathrm{n}$-butyl $\mathrm{cp}_{2} \mathrm{Fe}$ twin jet (TJ) deposition experiments indicated that a photochemical reaction occurs upon exposure to light from the $\mathrm{He} / \mathrm{Ne}$ calibration laser $(\lambda=632 \mathrm{~nm})$ or the IR source. The exposure to light from the IR spectrometer resulted in a change of the color of the matrix at the point where the calibrating laser and IR source passed through. This phenomenon was also observed in the $\mathrm{Ar} / \mathrm{O}_{3} / \mathrm{cp}_{2} \mathrm{Fe}$ experiments. ${ }^{23}$ All further experiments were performed by covering the cell windows during deposition.

Dark Deposition.No product bands were observed in the twin-jet, dark deposited spectrum of $\mathrm{Ar} / \mathrm{n}$-butyl $\mathrm{cp}_{2} \mathrm{Fe}+\mathrm{Ar} / \mathrm{O}_{3}$, other thanslightly red-shifted ozone absorptions (Figure S1). The matrix formed during the dark deposition was also a distinct green color (Figure S2a) whereas The colors of the $\mathrm{Ar} / \mathrm{O}_{3}$ and $\mathrm{Ar} / \mathrm{n}$-butyl $\mathrm{cp}_{2} \mathrm{Fe}$ matrices formed during the collection of the blanks were clear and pale yellow respectively. Annealing the matrix to $36 \mathrm{~K}$ did not lead to the formation of any product peaks nor any change in color of the matrix.Asimilar green matrix was also previously formed in the dark deposition of $\mathrm{Ar} / \mathrm{cp}_{2} \mathrm{Fe} / \mathrm{O}_{3}$, and the green colorthere was attributed to a $\mathrm{cp}_{2} \mathrm{Fe}-\mathrm{O}_{3}$ charge transfer complex. ${ }^{23}$ Evidence for the formation of these charge transfer complexes was based on the green color, suggesting strong red and blue absorptions in the visible spectrum, and slightly red-shifted ozone absorptions that are characteristic of perturbed ozone. ${ }^{30}$ Recently, a UV-vis study ${ }^{31}$ of the $\mathrm{O}_{3} / \mathrm{cp}_{2} \mathrm{Fe}$ and $\mathrm{O}_{3} /$ n-butyl $\mathrm{cp}_{2} \mathrm{Fe}$ systems led to the observation of a strong, broad electronic absorption in the $750-820 \mathrm{~nm}$ region for each system. Based on time-dependent DPT calculations, these bands were assigned to a 1:1 complex of $\mathrm{O}_{3}$ with $\mathrm{cp}_{2} \mathrm{Fe}$ and $\mathrm{n}$-butyl $\mathrm{cp}_{2}-\mathrm{Fe}$.Thus, we conclude that the green color of the matrix observed here and the shifted ozone vibrational bands are due to a 1:1 complex of $\mathrm{O}_{3}$ with $\mathrm{n}$ butyl $\mathrm{cp}_{2} \mathrm{Fe}$.

Photochemical Reaction. When the matrix was irradiated using the output from an 
incandescent light bulb filtered through a red glass cutoff filter (transmitting $\lambda \geq 600 \mathrm{~nm}$ ) a number of product bands were observed (Figure 2).
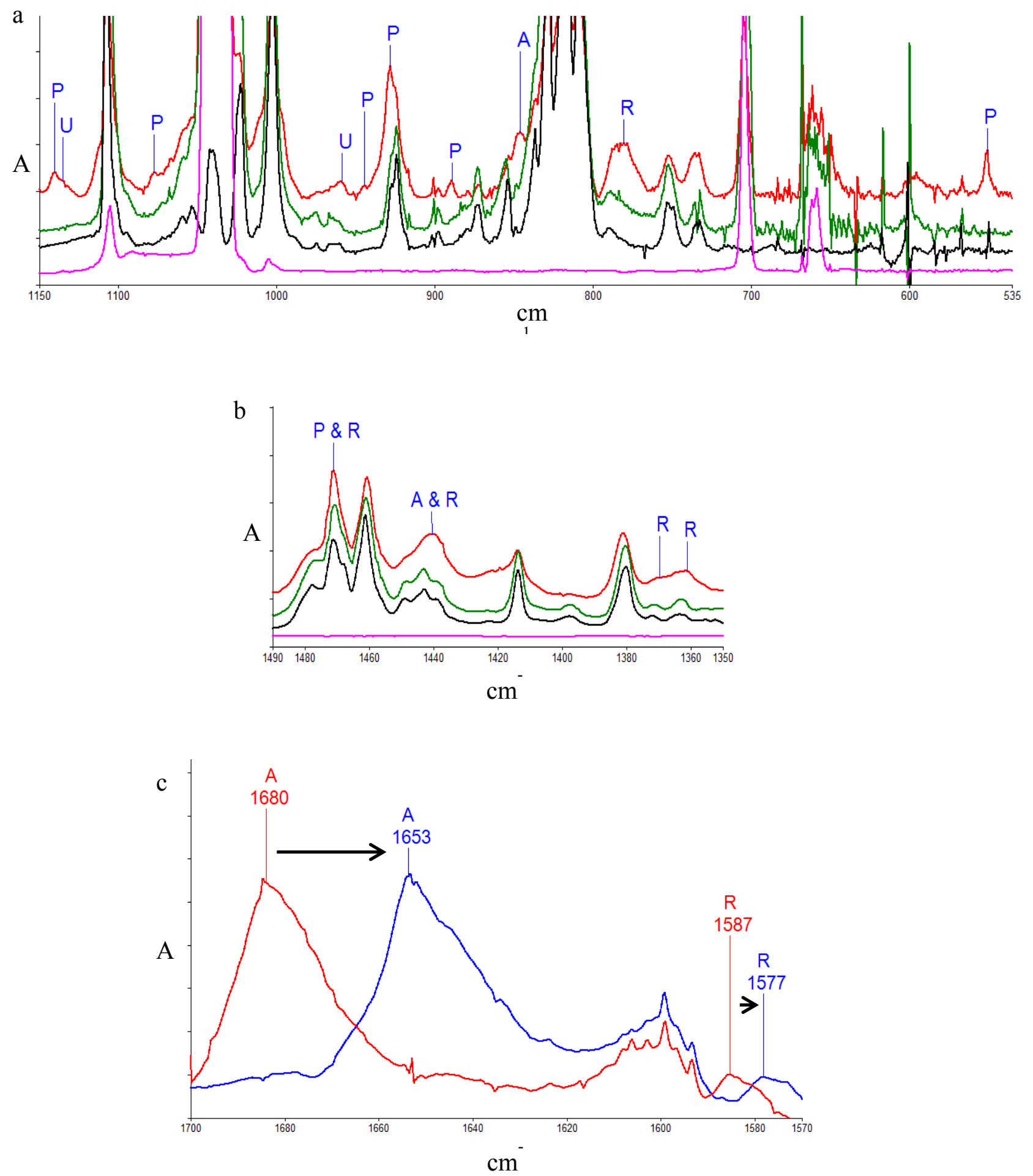
Figure 2Infrared absorption spectra (a) $\left(535-1150 \mathrm{~cm}^{-1}\right)$, (b) $\left(1350-1490 \mathrm{~cm}^{-1}\right)$, and (c) $\left(1570-1700 \mathrm{~cm}^{-1}\right)$ of: $\mathrm{Ar} /{ }^{16} \mathrm{O}_{3} / \mathrm{n}$-butylferrocene matrix after 1 hour red $\left(\lambda \geq 600 \mathrm{~nm}\right.$ ) irradiation (red trace), dark deposited $\mathrm{Ar} /{ }^{16} \mathrm{O}_{3} / \mathrm{n}$ butylferrocene (green trace), $\mathrm{Ar} / \mathrm{n}$-butylferrocene (black trace), $\mathrm{Ar} /{ }^{16} \mathrm{O}_{3}$ (pink trace), and $\mathrm{Ar} /{ }^{18} \mathrm{O}_{3} / \mathrm{n}$-butylferrocene after 30 min. red $(\lambda \geq 600 \mathrm{~nm}$ ) irradiation (blue trace). Peak assignments: $\mathrm{P}=$ pyran, $\mathrm{A}=$ aldehyde, $\mathrm{R}=$ ringaldehyde, $\mathrm{U}=$ unassigned.

Diagnostically significant product peaks were located in the $\mathrm{C}=\mathrm{O}$ stretching region at $1681 \mathrm{~cm}^{-1}$ and in the $\mathrm{C}-\mathrm{H}$ stretching region at $2712 \mathrm{~cm}^{-1}$. Several product peaks were also observed in the $\mathrm{C}-\mathrm{O}-\mathrm{C}$ stretching region. In addition to the formation of product peaks upon irradiation, a change in the in the color of the matrix from vivid green to red-orange was observed. Photographs of the green dark-deposited Ar/n-butyl $\mathrm{cp}_{2} \mathrm{Fe} / \mathrm{O}_{3}$ matrix prior to irradiation with red light and resulting red-orange matrix post irradiation are provided in the supplementary information(Figure S3). There are many similarities in the product peaks and color changes observed in both the Ar/n-butyl $\mathrm{cp}_{2} \mathrm{Fe} / \mathrm{O}_{3}$ and $\mathrm{Ar} / \mathrm{cp}_{2} \mathrm{Fe} / \mathrm{O}_{3}$ spectra after the irradiation with red light. $^{23}$

It has been documented in the literature that excitation of the Chappuis band $(420 \mathrm{~nm} \leq \lambda$ $\leq 700 \mathrm{~nm}$ ) leads to the photodissociation of $\mathrm{O}_{3} \cdot{ }^{30,32}$ Furthermore, Kugel, et al. observed isotope scrambling between ${ }^{18} \mathrm{O}_{3}$ and ${ }^{16} \mathrm{O}_{2}$ co-isolated in an Ar matrix after irradiation with red light $(\lambda \geq$ $600 \mathrm{~nm}) .{ }^{23}$ The irradiation of $\mathrm{O}_{3}$ with red light $(\lambda \geq 600 \mathrm{~nm})$ produces atomic oxygen, $\mathrm{O}\left({ }^{3} \mathrm{P}\right)$, and molecular oxygen, $\mathrm{O}_{2}\left({ }^{3} \Sigma\right)$. The $\mathrm{O}\left({ }^{3} \mathrm{P}\right)$ produced by red photolysis of $\mathrm{O}_{3}$ has up to $+23 \mathrm{kcal} / \mathrm{mol}$ of excess thermal energy. ${ }^{33}$ Calculations done during the vis/UV study of this system demonstrate a significant enhancement of the intensity of the long-wavelength of absorption of $\mathrm{O}_{3}$ in the $1: 1$ complex with n-butyl $\mathrm{cp}_{2} \mathrm{Fe}$, leading to enhanced $\mathrm{O}\left({ }^{3} \mathrm{P}\right)$ formation. The photochemical products observed here are proposed to be the result of a reaction between $\mathrm{O}\left({ }^{3} \mathrm{P}\right)$ and $\mathrm{n}$-butyl $\mathrm{cp}_{2} \mathrm{Fe}$ and not those of $\mathrm{O}_{3}$ and n-butyl $\mathrm{cp}_{2} \mathrm{Fe}$.

Based on the products observed in the literature for reactions of $\mathrm{O}\left({ }^{3} \mathrm{P}\right)$ with alkenes, the 
spectral similarities to the previous study of $\mathrm{Ar} / \mathrm{cp}_{2} \mathrm{Fe} / \mathrm{O}_{3}$, and the diagnostically significant peaks observed in the spectrum of irradiated Ar/n-butyl $\mathrm{cp}_{2} \mathrm{Fe} / \mathrm{O}_{3}$, several possible products were proposed. ${ }^{23,34-38}$ These proposed products consist of an iron atom with a coordinated nbutylcyclopentadienyl $(\mathrm{nBuCp})$ or cyclopentadienyl $(\mathrm{Cp})$ ring and either: (1) a pyran, (2) an aldehyde, or (3) a bidentate cyclic aldehyde with a seven-membered ring including the iron atom. However, in the case of n-butyl $\mathrm{cp}_{2} \mathrm{Fe}$ the butyl group on one of the $\mathrm{Cp}$ rings means that there are multiple regioisomers of the pyran (pyran-A-F), aldehyde (ald-A-I), and ring-aldehyde (rald-AE); as well as a ketone (keto) and ring-ketone (rketo) to consider. In addition, two conformational isomers of the aldehyde were also calculated. The two configurations are designated by the position of the hydrogen on the aldehyde group relative to the hydrogen or nbutyl group on the adjoining carbon atom. The aldehyde with oxygen atom pointing outwards and the hydrogens (or the n-butyl group and hydrogen) opposite of each other is designated the (E)-aldehyde (Figure 3a). The aldehyde with oxygen atom pointing inward and the hydrogens (or the n-butyl group and hydrogen) on the same side is designated the (Z)-aldehyde (Figure 3b).Table S1(in the supplementary information)gives calculated infrared vibrational frequencies, infrared intensities, and ${ }^{18} \mathrm{O}$-isotopic shifts of selected examples of these products. 


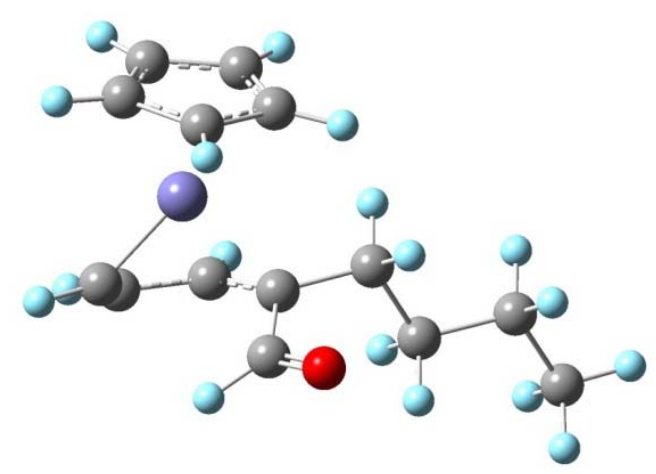

a) (E)-ald-A

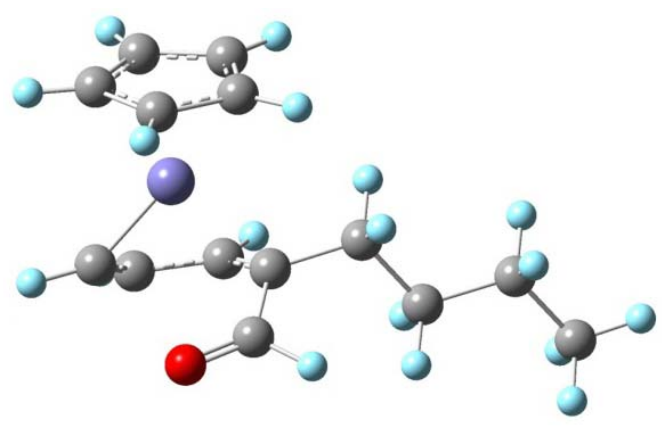

b) (Z)-ald-A

Figure 3 E/Z conformational isomers of aldehyde-A (ald-A). (a) The E conformation of Ald-1 with the hydrogen of the aldehyde group and n-butyl group (or the hydrogen, in the case of the other aldehydes) of the adjoining carbon are on opposite sides. (b) The $Z$ conformation of ald-A with the hydrogen of the aldehyde group and n-butyl group (or the hydrogen, in the case of the other aldehydes) of the adjoining carbon are on same sides.

Products formed from the reaction of $\mathrm{O}\left({ }^{3} \mathrm{P}\right)$ with the butyl group were not considered, given the presence of the conjugated cyclopentadienyl ring. The literature suggested thatalkyl substituent makes the reaction of atomic $\mathrm{O}$ with the unsaturated carbons more favorable. ${ }^{37}$ The reaction of $\mathrm{O}\left({ }^{3} \mathrm{P}\right)$ with alkenes was reported to occur through the addition of the $\mathrm{O}$ atom to a carbon of the double bond. ${ }^{34,37,38}$ The mechanism proposed and supported by theoretical 
calculations for the reaction of $\mathrm{cp}_{2} \mathrm{Fe}$ and $\mathrm{O}\left({ }^{3} \mathrm{P}\right)$ involves the addition of $\mathrm{O}\left({ }^{3} \mathrm{P}\right)$ to one of the ring carbons to form a biradical species where the oxygen atom is bound to one of the carbons in the cyclopentadienyl ring. This species then subsequently reacts to form the photo-products observed in the matrix. ${ }^{23}$ The mechanism proposed for the reaction of n-butyl $\mathrm{cp}_{2} \mathrm{Fe}$ and $\mathrm{O}\left({ }^{3} \mathrm{P}\right)$, discussed in detail in the following section is consistent with the formation of a biradical species in which the oxygen atom is bound to one of the ring carbons as the precursor for the products observed in the matrix after irradiation. A natural bond orbital (NBO) analysis of n-butyl $\mathrm{cp}_{2} \mathrm{Fe}$ shows that the charge density on the ring carbons is not uniform, as shown in Figure 1b. The ring carbon (C1) with the n-butyl substituent has a significantly lower negative-charge density than the other ring carbons. As a result it is unlikely that the electrophilic oxygen atom would bond to the $\mathrm{C} 1$ to form a biradical species. Furthermore, in reactions of atomic oxygen with alkenes, the preference for the initial oxygen atom to attack to occur at the least substituted carbon atom has been documented in the literature. ${ }^{38}$ This makes the formation of the ketone (keto) or ring-ketone (rketo), resulting from the initial formation of $\mathrm{C} 1$ biradical species, unlikely.

The calculated infrared vibrational frequencies and ${ }^{18} \mathrm{O}$-isotopic shifts for each of the $\mathrm{n}$ butyl $\mathrm{cp}_{2}$ Fepyran regioisomers show substantial similarities to oneanother. These similarities are also observed when comparing the calculated results of the n-butyl $\mathrm{cp}_{2}$ Fealdehyde regioisomers and structural isomers to each other.Given the uncertainty associated with the calculated spectra and ${ }^{18} \mathrm{O}$-isotopic shifts, the calculated spectra do not allow for the distinction between regioisomers of a given pyran or aldehyde based on spectroscopy. However, some of the ringaldehyde regioisomers' calculated spectra do show some significant differences that can be used to eliminate some from consideration. Both rald-Aand -Dare calculated to have intense peaks with ${ }^{18} \mathrm{O}$-isotopic shifts which were not observed in the irradiated experimental spectra. 
Figure 2 show spectra of the TJ-dark-codeposited matrix of $\mathrm{O}_{3}$ and n-butyl $\mathrm{cp}_{2} \mathrm{Fe}$ in argon after red irradiation and Table 1lists the product peaks and assignments. It is likely that multiple regioisomers of each species are present in the matrix. Thus, assignments of product peaks are made to a group of regioisomers and not to a specific member of that group. However, for comprehensibility of the table only the calculated vibrational frequencies and ${ }^{18} \mathrm{O}$-isotopic shifts of the regioisomer that best matches the assigned peak are given in Table 1. 
Table 1 Band Positions and Assignments for the Products from the Twin Jet Deposition of Ozone with n-Butylferrocene upon Irradiation with Light of $\lambda \geq 600 \mathrm{~nm}$.

\begin{tabular}{ccccc} 
& & \multicolumn{2}{c}{${ }^{18} \mathrm{O}$} & \\
\cline { 2 - 4 } exptl bands $^{\mathrm{a}}$ & calcd bands $^{\mathrm{b}}$ & $\begin{array}{c}\text { calcd } \\
\text { shift }^{\mathrm{b}}\end{array}$ & $\begin{array}{c}\text { exptl } \\
\text { shift }\end{array}$ & assignments \\
\hline $551(\mathrm{~m})$ & 559 & -6 & -7 & pyran \\
$781(\mathrm{~m})$ & 755 & 0 & -1 & ring-aldehyde \\
$846 \mathrm{sh}(\mathrm{vw})$ & 841 & 0 & 0 & aldehyde \\
$889(\mathrm{~m})$ & 894 & -4 & -6 & pyran \\
$927(\mathrm{~s})$ & 956 & -7 & -8 & pyran \\
$945(\mathrm{vw})$ & 961 & -11 & -13 & pyran \\
$959(\mathrm{vw})$ & & & -4 & \\
$1078(\mathrm{~m})$ & 1091 & -5 & -4 & pyran \\
$1135(\mathrm{vw})$ & & & -8 & \\
$1140(\mathrm{~m})$ & 1160 & -4 & -5 & pyran \\
$1164(\mathrm{vw})$ & $1199 / 1196$ & $-2 / 0$ & -1 & pyran/aldehyde \\
$1360(\mathrm{vw})$ & 1330 & -1 & 0 & ring-aldehyde \\
$1372(\mathrm{vw})$ & 1339 & -2 & -3 & ring-aldehyde \\
$1440(\mathrm{~m})$ & $1455 / 1465$ & 0 & 0 & aldehyde/ring-aldehyde \\
$1471(\mathrm{w})$ & $1512 / 1471,1474$ & 0 & 0 & pyran/ring-aldehyde \\
$1583(\mathrm{~m})$ & 1608 & -6 & -6 & ring-aldehyde \\
$1680(\mathrm{vs})$ & 1747 & -35 & -27 & aldehyde \\
$2712(\mathrm{~m})$ & 2902 & 0 & 0 & aldehyde \\
\hline
\end{tabular}

${ }^{\text {a }}$ Frequencies in $\mathrm{cm}^{-1}$

${ }^{\mathrm{b}}$ Calculated at the B3LYP/6-311G $++(\mathrm{d}, 2 \mathrm{p})$ level of theory, unscaled.

Reaction Mechanism. The proposed photochemical reaction between n-butyl $\mathrm{cp}_{2} \mathrm{Fe}$ and $\mathrm{O}_{3}$ starts with production of ground state atomic oxygen with up to as much as $+23 \mathrm{kcal} / \mathrm{mol}$ of excess thermal energy by photolysis at $\lambda \geq 600 \mathrm{~nm}$, as discussed in the previous section. ${ }^{33}$ Based on the products observed in the spectra after irradiation and literature for reactions of $\mathrm{O}\left({ }^{3} \mathrm{P}\right)$ with alkenes ${ }^{34-37}$ a possible general reaction of $\mathrm{O}\left({ }^{3} \mathrm{P}\right)$ and n-butyl $\mathrm{cp}_{2} \mathrm{Fe}$ is shown in Scheme 1:

Scheme 1. Proposedgeneral schemefor the $(\lambda \geq 600 \mathrm{~nm})$ photochemical reaction between $O\left({ }^{3} P\right)$ and n-butyl cp2Fe.

(1) $\quad \mathrm{O}\left({ }^{3} \mathrm{P}\right)+$ n-butyl $\mathrm{cp}_{2} \mathrm{Fe} \rightarrow$ n-butyl $\mathrm{cp}_{2} \mathrm{Fe}-\mathrm{O}($ biradical $) \rightarrow$ n-butyl $\mathrm{cp}_{2} \mathrm{FeO}$ (pyran) 
(2) $\quad \mathrm{O}\left({ }^{3} \mathrm{P}\right)+$ n-butyl $\mathrm{cp}_{2} \mathrm{Fe} \rightarrow$ n-butyl $\mathrm{cp}_{2} \mathrm{Fe}-\mathrm{O}$ (biradical) $\rightarrow$ n-butyl $\mathrm{cp}_{2} \mathrm{FeO}$ (aldehyde)

(3) n-butyl $\mathrm{cp}_{2} \mathrm{FeO}$ (pyran) $\rightarrow$ n-butyl $\mathrm{cp}_{2} \mathrm{FeO}$ (aldehyde)

(4) n-butyl $\mathrm{cp}_{2} \mathrm{FeO}$ (aldehyde) $\rightarrow$ n-butyl $\mathrm{cp}_{2} \mathrm{FeO}$ (ring-aldehyde)

The $\mathrm{O}\left({ }^{3} \mathrm{P}\right)$ can react with $\mathrm{n}$-butyl $\mathrm{cp}_{2} \mathrm{Fe}$ to form either a pyran (1) and an aldehyde (2). The aldehyde can then subsequently form the ring-aldehyde (4). Reaction (4) is based on the presence of infrared peaks assigned to the ring-aldehyde after red photolysis $(\lambda \geq 600 \mathrm{~nm})$ which are not significantly present after infrared photolysis $(\lambda \geq 1000 \mathrm{~nm})$. Reaction (3) is the conversion of the pyran through a ring opening to form the aldehyde. Although the average energy of the aldehyde is $11 \mathrm{kcal} / \mathrm{mol}$ higher than the average energy of the pyran, reaction (3) could still be possible given the excess energy available from the initial exothermic formation of the pyran product. Figure 4 gives the reaction potential energy diagram for the formation of pyran-A, reaction (1) and ald-A, reactions (2) and (3).

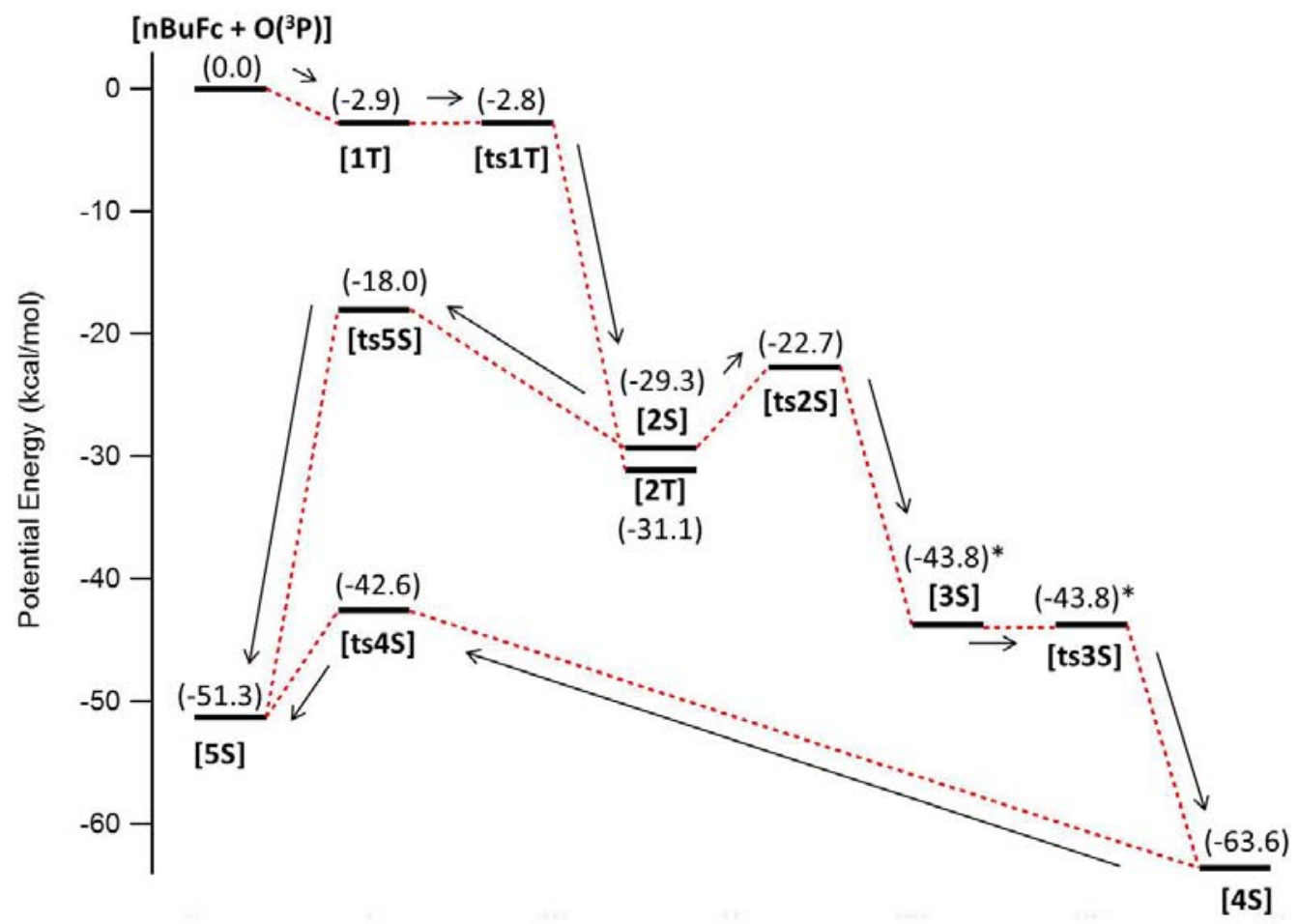


Figure 4 Calculated potential energy diagram for n-butyl $\mathrm{cp}_{2} \mathrm{Fe}+\mathrm{O}\left({ }^{3} \mathrm{P}\right) \rightarrow$ pyran- $\mathrm{A}+$ ald-A. [n-butyl $\left.\mathrm{cp}_{2} \mathrm{Fe}+\mathrm{O}\left({ }^{3} \mathrm{P}\right)\right]$ $=$ uncomplexed $\mathrm{n}$-butyl $\mathrm{cp}_{2} \mathrm{Fe}$ and $\mathrm{O}\left({ }^{3} \mathrm{P}\right) ;[1 \mathrm{~T}]=$ a triplet van der Waals complex between $\mathrm{n}$-butyl $\mathrm{cp}_{2} \mathrm{Fe}+\mathrm{O}\left({ }^{3} \mathrm{P}\right)$; $[$ ts $1 \mathrm{~T}]=$ transition state 1 for the formation of the triplet biradical; $[2 \mathrm{~T}]=$ triplet biradical; $[2 \mathrm{~S}]=$ singlet biradical; $[$ ts $2 \mathrm{~S}]=$ transition states connecting singlet biradical with singlet epoxide. [3S] $=$ singlet epoxide; [ts3S] $=$ transition states connecting singlet epoxide with singlet pyran-A; $[4 \mathrm{~S}]=$ singlet pyran-A; [ts $4 \mathrm{~S}]=$ transition state connecting singlet pyran-A, [4S], with the singlet aldehyde; $[5 \mathrm{~S}]=$ singlet aldehyde; [ts5S] $=$ transition state connecting biradical, [2S], with singlet aldehyde, [5S]. The energies* and structures of the epoxide, [3S], and the transition states, [ts3S] connecting singlet epoxide with singlet pyran-A are derived from the an IRC calculation.

The calculated structures corresponding to potential energy diagrams are given in Figure S3. The calculated structures suggest that the transition states are accessible once $\mathrm{O}\left({ }^{3} \mathrm{P}\right)$ is formed via irradiation with $\lambda \geq 600 \mathrm{~nm}$ and that the reactions (2) and (3) involve a stable but unobserved biradical $[2 \mathrm{~T} \rightarrow 2 \mathrm{~S}]$ and an epoxide $[3 \mathrm{~S}]$. The diagram starts with addition of $\mathrm{O}\left({ }^{3} \mathrm{P}\right)$ to carbon 2 (C2) to form a triplet van der Waals complex (T-vdW-C2), [1T]. The calculations show that these species can react in an essentially barrierless exothermic reaction to form a triplet biradical (T-BR-C2), [2T]. This triplet biradical can undergo an intersystem crossing to form the corresponding singlet biradical (S-BR-C2), [2S]. The S-BR-C2, [2S], can rearrange to yield an epoxide (S-epox-A), [3S]. The epoxide can undergo further rearrangement to form the pyran (pyran-A) from reaction (1). It should be noted that although a stable S-epox-Acould not be located, evidence for its transitory presence comes from the IRC calculated for the transition of S-BR-C2 to pyran-A. This is likely due to a low activation energy barrier for the formation of pyran-A. The energies and structures given for $[3 \mathrm{~S}]$ and $[\mathrm{ts} 3 \mathrm{~S}]$ in Figure 4 are derived from the IRC calculation and the IRC is provided in Figure S4. In addition to forming pyran-A, S-BR-C2, [2S], can also rearrange to yield an aldehyde (S-ald-A), [5S], by reaction (2), and this rearrangementhas an activation barrier of $11.3 \mathrm{kcal} / \mathrm{mol}$. Pyran-Acan also undergo a ring opening to form ald-A by reaction (3), and that this reaction has an activation energy barrier of $21.0 \mathrm{kcal} / \mathrm{mol}$. The mechanism proposed for reaction of $\mathrm{n}$-butyl $\mathrm{cp}_{2} \mathrm{Fe}$ and $\mathrm{O}\left({ }^{3} \mathrm{P}\right)$ is complicated by the multiple regioisomers of each product. The full reaction mechanism proposed when $\mathrm{O}\left({ }^{3} \mathrm{P}\right)$ reacts with $\mathrm{C} 2$ to form $(\mathrm{T}-\mathrm{vdW}-\mathrm{C} 2)$ is given in Figure 5. It proposes that $\mathrm{S}-\mathrm{BR}-\mathrm{C} 2,[2 \mathrm{~S}]$, can 
also form pyran-B, ald-B, and rald-B. Thesepathways indicate that reactions (1) - (4) and the regioisomers of products may be connected by an unobserved singlet biradical. rald-Awas not listed as a product since it was previously established not to be present in the matrix based on its calculated IR spectrum.

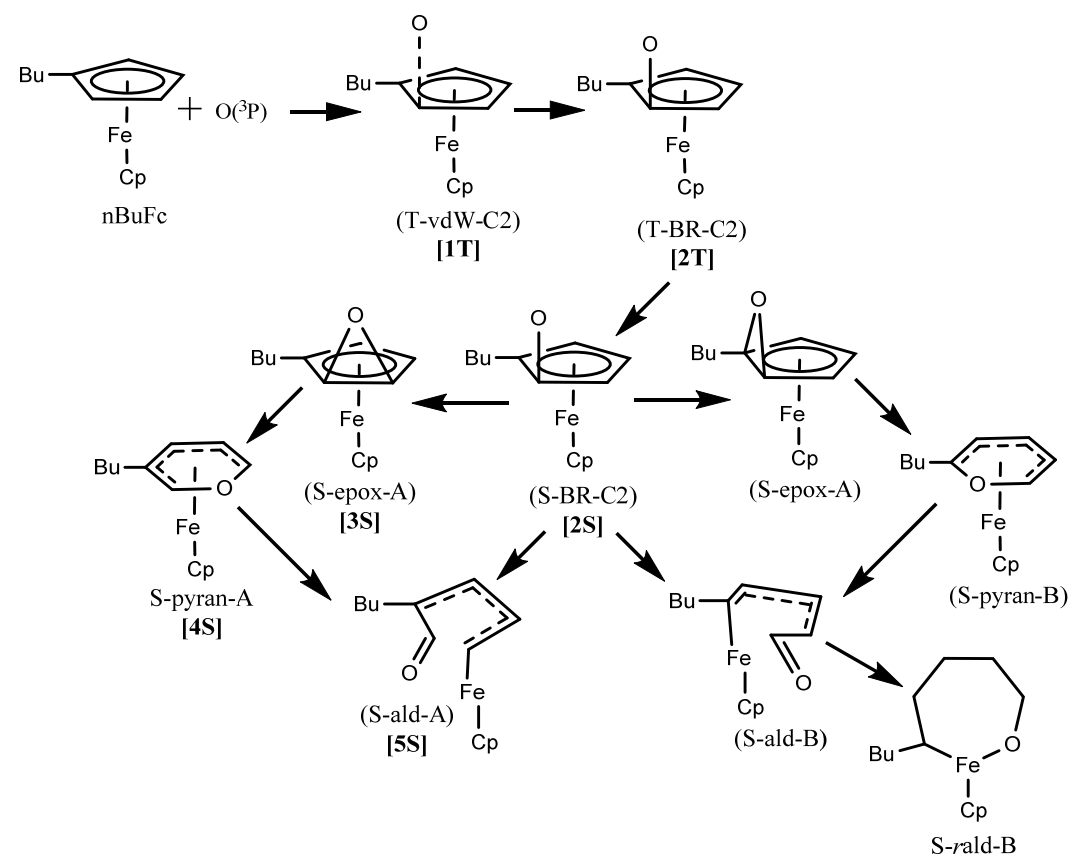

Figure 5 The full reaction scheme proposed when $\mathrm{O}\left({ }^{3} \mathrm{P}\right)$ reacts with $\mathrm{C} 2$ of n-butylferrocene to form T-vdW-C2.

The formation of the photochemical products' remaining regioisomers are proposed to follow the same reaction mechanism discussed above; which starts with addition of $\mathrm{O}\left({ }^{3} \mathrm{P}\right)$ to a carbon in either ring of n-butyl $\mathrm{cp}_{2} \mathrm{Fe}$ to form a triplet van der Waals complex (T-vdW). However, the formation of a T-vdW complex involving the $\mathrm{C} 1$ carbon is unlikelygiven that this ring carbon is calculated have a significantly lower charge density than the other ring carbons (Figure 1b). As a consequence the formation of resulting ketone (keto) and ring-ketone (rketo) would be unlikely. Although the formation of the keto and rketo cannot be totally eliminated as they could be formed from pyran-Avia reactions (3) and (4) they would likely not be significant products. The mechanism of the reaction resulting in the formation of regioisomers involving 
cyclopentadienyl ring carbons (C6-C10) of n-butyl $\mathrm{cp}_{2} \mathrm{Fe}$ (pyran-D -F, ald-E -I, and rald-E) are proposed to follow the same mechanism as that given for $\mathrm{cp}_{2} \mathrm{Fe}$ and $\mathrm{O}\left({ }^{3} \mathrm{P}\right) .{ }^{23}$

\section{Conclusions}

There is strong evidence that upon irradiation with $\lambda \geq 600 \mathrm{~nm}$ theinitial step in thephotochemical reaction of n-butyl $\mathrm{cp}_{2} \mathrm{Fe}$ and $\mathrm{O}_{3}$ isphotodissociation of $\mathrm{O}_{3}$. This yields a highly reactive atomic oxygen, $\mathrm{O}\left({ }^{3} \mathrm{P}\right)$, and molecular oxygen, $\mathrm{O}_{2}\left({ }^{3} \Sigma\right)$. $\mathrm{O}\left({ }^{3} \mathrm{P}\right)$ reacts with n-butyl $\mathrm{cp}_{2}$ Feto produce the observed photochemical products. These productscontain an iron atom with a coordinated n-butylcyclopentadienyl or cyclopentadienyl ring and either: (1) a pyran, (2) an aldehyde, or (3) a bidentate cyclic aldehyde with a seven-membered ring including the iron atom. We were unable to assign the specific regioisomers and conformational isomers of each product present due to similarities the calculated spectra. It is likely that multiple regioisomers of each product are present in the matrix and the potential energy diagram of the reaction mechanism shows multiple paths to some products.Furthermore, n-butyl group may have some effect on the formation of some regioisomers by altering the charge distribution of ring carbons in n-butyl $\mathrm{cp}_{2} \mathrm{Fe}$. A reaction of $\mathrm{O}_{3}$ with a ferrocene that has a substituent group that strongly affects charge distribution, such as an amine group, merits further investigation. Lastly, the green matrix formed during the initial dark deposition of $\mathrm{O}_{3}$ with n-butyl $\mathrm{cp}_{2}$ Fedue to the formation of an $\mathrm{n}$ butyl $\mathrm{cp}_{2} \mathrm{Fe}-\mathrm{O}_{3}$ charge transfer complex.

\section{Acknowledgments}

The authors wish to thank Roger Kugel and Anna Gudmundsdottir for helpful discussions. The authors also gratefully acknowledge support of this research by the National Science Foundation under Grant CHE 1110026. 


\section{References}

[1] C. Pflitsch, D. Viefhaus, U. Bergmann, V. Kravets, H. Nienhaus, B. Atakan, Growth of thin iron oxide films on $\mathrm{Si}(100)$ by MOCVD, Journal of the Electrochemical Society, 153 (2006) C546-C550.

[2] M.K. Singh, Y. Yang, C.G. Takoudis, Low-Pressure Metallorganic Chemical Vapor Deposition of Fe2O3 Thin Films on $\mathrm{Si}(100)$ Using n-Butylferrocene and Oxygen, Journal of the Electrochemical Society, 155 (2008) D618-D623.

[3] S.M. George, B.K. Park, C.G. Kim, T.M. Chung, Heteroleptic Group 2 Metal Precursors for Metal Oxide Thin Films, European Journal of Inorganic Chemistry, (2014) 2002-2010.

[4] J.F. Conley, Y. Ono, D.J. Tweet, R. Solanki, Pulsed deposition of metal-oxide thin films using dual metal precursors, Applied Physics Letters, 84 (2004) 398-400.

[5] P. Roura, J. Farjas, H. Eloussifi, L. Carreras, S. Ricart, T. Puig, X. Obradors, Thermal analysis of metal organic precursors for functional oxide preparation: Thin films versus powders, Thermochimica Acta, 601 (2015) 1-8.

[6] J.P. Collman, Principles and applications of organotransition metal chemistry, University Science Books, Mill Valley, Calif., 1987.

[7] S.J. Moss, A. Ledwith, Chemistry of the Semiconductor Industry, Springer, 1989.

[8] B. Tan, $\mathrm{Y}$. Wu, Dye-sensitized solar cells based on anatase $\mathrm{TiO}_{2}$ nanoparticle/nanowire composites, The journal of physical chemistry. B, 110 (2006) 15932-15938.

[9] D.M. Mattox, Chapter 1 - Introduction, in: D.M. Mattox (Ed.) Handbook of Physical Vapor Deposition (PVD) Processing (Second Edition), William Andrew Publishing, Boston, 2010, pp. $1-24$.

[10] T. Kääriäinen, D. Cameron, M.-L. Kääriäinen, A. Sherman, Fundamentals of Atomic Layer Deposition, Atomic Layer Deposition, John Wiley \& Sons, Inc.2013, pp. 1-31.

[11] A.H.M. Jones, Overview of Chemical Vapour Deposition, in: A.H.M. Jones (Ed.) Chemical vapour deposition: precursors, processes and applications, Royal Society of Chemistry, Cambridge, 2009, pp. 1-33.

[12] H. Sundstrom, C. Gottschalk, The Evolution of Ozone Subsystems, Semiconductor International, DOI (2006) 2-5.

[13] S.K. Kim, C.S. Hwang, S.H.K. Park, S.J. Yun, Comparison between $\mathrm{ZnO}$ films grown by atomic layer deposition using $\mathrm{H}_{2} \mathrm{O}$ or $\mathrm{O}_{3}$ as oxidant, Thin Solid Films, 478 (2005) 103-108.

[14] S.-C. Ha, E. Choi, S.-H. Kim, J.S. Roh, Influence of oxidant source on the property of atomic layer deposited $\mathrm{Al}_{2} \mathrm{O}_{3}$ on hydrogen-terminated Si substrate, Thin Solid Films, 476 (2005) 252-257. 
[15] H.B. Park, M.J. Cho, J. Park, S.W. Lee, C.S. Hwang, J.P. Kim, J.H. Lee, N.I. Lee, H.K. Kang, J.C. Lee, S.J. Oh, Comparison of $\mathrm{HfO}_{2}$ films grown by atomic layer deposition using $\mathrm{HfCl}_{4}$ and $\mathrm{H}_{2} \mathrm{O}$ or $\mathrm{O}_{3}$ as the oxidant, Journal of Applied Physics, 94 (2003) 3641-3647.

[16] K. Široký, J. Jirešová, L. Hudec, Iron oxide thin film gas sensor, Thin Solid Films, 245 (1994) 211-214.

[17] Y.M. Lin, P.R. Abel, A. Heller, C.B. Mullins, $\alpha-\mathrm{Fe}_{2} \mathrm{O}_{3}$ nanorods as anode material for lithium ion batteries, The Journal of Physical Chemistry Letters, 2 (2011) 2885-2891.

[18] J. Jiang, Y. Li, J. Liu, X. Huang, C. Yuan, X.W. Lou, Recent advances in metal oxide-based electrode architecture design for electrochemical energy storage, Adv Mater, 24 (2012) 51665180 .

[19] K. Sivula, F. Le Formal, M. Grätzel, Solar water splitting: progress using hematite $\left(\alpha-\mathrm{Fe}_{2} \mathrm{O}_{3}\right)$ photoelectrodes, ChemSusChem, 4 (2011) 432-449.

[20] N. Beermann, L. Vayssieres, S.E. Lindquist, A. Hagfeldt, Photoelectrochemical studies of oriented nanorod thin films of hematite, Journal of the Electrochemical Society, 147 (2000) 2456-2461.

[21] A.B. Murphy, P.R.F. Barnes, L.K. Randeniya, I.C. Plumb, I.E. Grey, M.D. Horne, J.A. Glasscock, Efficiency of solar water splitting using semiconductor electrodes, International Journal of Hydrogen Energy, 31 (2006) 1999-2017.

[22] Y. Yang, Q. Tao, G. Srinivasan, C.G. Takoudis, Cyclic Chemical Vapor Deposition of Nickel Ferrite Thin Films Using Organometallic Precursor Combination, Ecs Journal of Solid State Science and Technology, 3 (2014) P345-P352.

[23] R.W. Kugel, L.F. Pinelo, B.S. Ault, Infrared Matrix-Isolation and Theoretical Studies of the Reactions of Ferrocene with Ozone, J Phys Chem A, DOI 10.1021/jp5074889(2014).

[24] B.S. Ault, Infrared spectra of argon matrix-isolated alkali halide salt/water complexes, Journal of the American Chemical Society, 100 (1978) 2426-2433.

[25] M.J.T. Frisch, G. W.; Schlegel, H. B.; Scuseria, G. E.; Robb, M. A.; Cheeseman, J. R.; Scalmani, G.; Barone, V.; Mennucci, B.; Petersson, G. A.; Nakatsuji, H.; Caricato, M.; Li, X.; Hratchian, H. P.; Izmaylov, A. F.; Bloino, J.; Zheng, G.; Sonnenberg, J. L.; Hada, M.; Ehara, M.; Toyota, K.; Fukuda, R.; Hasegawa, J.; Ishida, M.; Nakajima, T.; Honda, Y.; Kitao, O.; Nakai, H.; Vreven, T.; Montgomery, Jr., J. A.; Peralta, J. E.; Ogliaro, F.; Bearpark, M.; Heyd, J. J.; Brothers, E.; Kudin, K. N.; Staroverov, V. N.; Kobayashi, R.; Normand, J.; Raghavachari, K.; Rendell, A.; Burant, J. C.; Iyengar, S. S.; Tomasi, J.; Cossi, M.; Rega, N.; Millam, J. M.; Klene, M.; Knox, J. E.; Cross, J. B.; Bakken, V.; Adamo, C.; Jaramillo, J.; Gomperts, R.; Stratmann, R. E.; Yazyev, O.; Austin, A. J.; Cammi, R.; Pomelli, C.; Ochterski, J. W.; Martin, R. L.; Morokuma, K.; Zakrzewski, V. G.; Voth, G. A.; Salvador, P.; Dannenberg, J. J.; Dapprich, S.; Daniels, A. D.; Farkas, Ö.; Foresman, J. B.; Ortiz, J. V.; Cioslowski, J.; Fox, D. J., Gaussian 09, Gaussian, Inc., Wallingford CT, 2009. 
[26] Butylferrocene (97\%) FT-IR spectrum, The Aldrich Library of FT-IR spectra, Aldrich1997, pp. 4569-D.

[27] Butylferrocene FT-IR spectrum Liquid Film (SDBS-NO=10729), National Institute of Advanced Industrial Science Technology.

[28] D.S. Margolis, C. Tanjaroon, S.G. Kukolich, Measurements of microwave spectra and structural parameters for methylferrocene, Journal of Chemical Physics, 117 (2002) 3741-3747.

[29] R. Subramanian, C. Karunatilaka, K.S. Keck, S.G. Kukolich, The gas phase structure of ethynylferrocene using microwave spectroscopy, Inorganic Chemistry, 44 (2005) 3137-3145.

[30] M. Bahou, L. SchriverMazzuoli, A. Schriver, P. Chaquin, Structure and selective visible photodissociation of the $\mathrm{O}_{3}: \mathrm{Br}_{2}$ and $\mathrm{O}_{3}: \mathrm{BrCl}$ complexes: An infrared matrix isolation and $\mathrm{ab}$ initio study, Chemical Physics, 216 (1997) 105-118.

[31] L.F. Pinelo, R.W. Kugel, B.S. Ault, Charge-Transfer Complexes and Photochemistry of Ozone with Ferrocene and n-Butylferrocene: A UV-vis Matrix-Isolation Study, The Journal of Physical Chemistry A, 119 (2015) 10272-10278.

[32] M. Bahou, L. Schriver-Mazzuoli, C. Camy-Peyret, A. Schriver, Photolysis of ozone at 693 $\mathrm{nm}$ in solid oxygen. Isotopic effects in ozone reformation, Chemical Physics Letters, 273 (1997) 31-36.

[33] D.D. Wagman, American Chemical Society, American Institute of Physics, United States, National Bureau of Standards, The NBS tables of chemical thermodynamic properties : selected values for inorganic and C1 and C2 organic substances in SI units, ACS and AIP for NBS1982.

[34] G. Boocock, R.J. Cvetanović, Reaction of oxygen atoms with benzene, Canadian Journal of Chemistry, 39 (1961) 2436-2443.

[35] R.J. Cvetanović, Evaluated chemical kinetic data for the reactions of atomic oxygen O (3P) with unsaturated hydrocarbons, Journal of physical and chemical reference data, 16 (1987) 261326.

[36] R.J. Cvetanović, Relative rates of reactions of oxygen atoms with olefins, The Journal of chemical physics, 30 (1959) 19-26.

[37] B. Messaoudi, S. Mekelleche, N. Mora-Diez, Theoretical study of the complex reaction of O(3P) with cis-2-butene, Theoretical Chemistry Accounts, 132 (2013) 1-7.

[38] Z. Min, T.-H. Wong, H. Su, R. Bersohn, Reaction of O(3P) with Alkenes: Side Chain vs Double Bond Attack, The Journal of Physical Chemistry A, 104 (2000) 9941-9943. 